\title{
ASSESSMENT OF GENDER DIFFERENCES IN PRODUCTIVITY AMONG RURAL HOUSEHOLDS IN SOUTH WEST, NIGERIA
}

\author{
Nurudeen Afolabi Sofoluwe \\ Department of Cooperative and Rural Development Olabisi Onabanjo University, Ago-Iwoye, \\ Ogun State, Nigeria. \\ E-mail: nasofoluwe@gmail.com
}

Citation: Sofoluwe, N.A. 2019. Assessment of Gender Differences in Productivity Among Rural Households in South West, Nigeria. J. Asian Rur. Stud. 3(2): 196-207

\begin{abstract}
Increase in productivity across gender line is one of the necessary conditions for sustainable level of development in the rural areas. This study assessed the differences in productivity of men and women in rural households in Southwest, Nigeria. Average and marginal productivity of women and men were assessed. Gender-disaggregated data were obtained through structured questionnaires. Using multi stage sampling approach, a total of 197 and 148 men and women rural households were randomly sampled. Cobb Douglas production function was used to analyse differentials in productivity between women and men. The results showed that women have access to marginal and small pieces of land. Men with access to improved technology have significantly $(\mathrm{p}<0.05)$ higher productivity per unit of most of the inputs available. Also, the result indicates that the estimated average productivities of women are significantly lower than those of men. Furthermore, ownership of land has a significant positive influence on the estimated productivity of men more than women. Education which is another gender factor and a measure of human asset and managerial capacity significantly $(\mathrm{p}<$ $0.05)$ increased the productivity of men $(\beta=0.11, t=3.04)$ and women $(\beta=0.07, t=3.86)$. In order to raise productivity and impacts development agenda for the rural sector, it would be better for women to keep the variable resource in surplus rather than utilizing it in a fixed resource contrary to what is obtainable for men.
\end{abstract}

Keywords: Asset; Cobb-Douglas; Gender; Productivity; Rural Households

\section{Introduction}

Gains from gender balance in productivity could positively influence rural development. The objective of attaining desirable level of development in the rural areas may depend largely on increases in productivity. Hence, identifying the causes of gender related differences in productivity of rural households is crucial to understanding the path to sustainable rural development. Studies on gender differentials have attracted growing interest in the literature because of unanticipated changes in productivity in the presence of ever evolving developmental technologies. In the rural areas with large presence of agrarian activities, productivity growth is a necessary condition for the survival of a farm-firm, reduction of poverty and enhancement of productive asset of farmers (Heikkilä, Myyrä, and Pietola, 2012). Broad increases in productivity can reduce poverty by raising productive assets of the rural poor and generating important spill-over effects to the rest of the economy (Sofoluwe, 2015). Hence, one of the 
objectives of rural development programmes and interventions is to raise productivity with the expectation that increase in productivity would translate into overall well-being of the rural populace. But, the objective of raising productivity requires among others, investments in new productive enhancing technology for the rural poor such as improved seed varieties and large scale usage of such technologies by all irrespective of their gender (Ragaza, 2012).

The need to broaden usage of improved technology across gender, which is defined as a socially constructed role of male and female (Deji, 2011) is premised on the findings that local gender relations play a significant role in the translation of economic benefits derived from technological uptake into increased productivity, individual wellbeing and greater assets acquisition (Padmaja, 2006). Recognizing the gender role in increasing productivity, many development interventions have disclosed the need to close the gender gap in access to resources, and address the specific needs of all individuals across gender line.

While there are several theoretical agreements that gender differential in the use of agricultural technology limits productivity (World Bank, 2007) and several approaches developed to streamline gender-specific initiatives (Quisumbing and Pandolfelli, 2010), there is a lack of consensus on actual magnitude of gender differentials on productivity and asset acquisition (Peterman et al., 2010). Further existing studies on gender differentials in the use of technology to drive productivity are few (Odurukwe, 2003). Thus, biased estimates of productivity differentials among male and female households are usually presented.

Most studies on male-female differences are biased towards female gender. Quisumbing (1996) reviewed the econometric evidence on gender differences in agricultural productivity. Specifically, he provided a methodological overview and a critique of production function-based estimates of technical and labour productivity differences by gender; individual (gender-disaggregated) labour supply and earnings functions and studies of the determinants of technological adoption. Based on secondorder Taylor's expansions which was used to approximate the functional form (for example, the translog, normalized quadratic and Leontief) in addition to generalized Cobb-Douglas function, the study found that in general, male and female farmers are equally efficient as farm managers. However, women farmers have lower yields which are attributable to lower levels of inputs and assets such as human capital than men.

Padmaja et al. (2006) explored gender-differentiated benefits from the capital asset build up in groundnut technology uptake, and the decision-making patterns of men and women with respect to production, consumption and household task in India. The allocation of resources among male and female farmers was compared using 'with' and 'without' groundnut technology situations, and 'before' and 'after' the technology situations. Their findings showed that women who are engaged in agriculture developed bonding social capital characterized by strong bonds such as that found among family members or among members of an ethnic group. Schmidt and Sevak (2006) examined the influence of gender on asset accumulation of households in United State of America. Using quantile regression, their results showed that significant wealth gap persists between households based on both gender. However, the findings are not attributed to differences in access to resources. 
Agboh-Noameshie et al. (2007) examined gender impact of NERICA adoption on farmers' production and income in central Benin Republic. They employed econometric method based on Local Average Treatment effect (LATE) to estimate the impact of gender differences in adoption on farmers' yield and income. The results showed that adoption has positive and significant impact on farmers' yield and income. The impacts of adoption are higher among women farmers than men farmers.

Thapa (2009) analyzed gender productivity differentials in the peasant agriculture in Nepal. Both Cobb-Douglas and translog production functions were estimated using data from the Nepal Living Standard Survey. Evidence was found for higher value of marginal product of adult family male than adult female, while marginal products of other inputs were found to be relatively higher than the prevailing market wages and prices, implying that these inputs have become gradually a binding constraint in production. Male managed farms produce more output per hectare with higher command in market input use, obtaining credit, and receiving agricultural extension services than female managed farms. In contrast, the result did not clearly support the hypothesis of separability or aggregation of male and female labour, but there is little justification of weak separability. Moreover, head's sex as proxy for farm manager does not show any difference between male and female managed farms. However, the coefficients of location and household characteristics showed significant variations in farm output among ethnic and caste groups residing in different ecological belts of Nepal. Overall, adult male labour is found to contribute more to production process than adult female labour.

Alene et al. (2008) assessed the relative economic efficiency and output supply and input demand responses of women farmers in western Kenya. Using normalized restricted profit function, the results showed that women are as technically and allocatively efficient as men. However, neither men nor women have absolute allocative efficiency. Women farmers are equally responsive to price incentives in terms of output supply and input demand.

Adekambi et al. (2009) examined the relationship between agricultural technology adoption and poverty through gender lens, with a focus on New Rice varieties for Africa (NERICA). The paper used the counterfactual outcomes framework of modern evaluation theory to estimate the Local Average Treatment Effect (LATE) of NERICA adoption on household expenditure among 268 households from rural Benin Republic. The impact is higher among female-headed households than male-headed households.

Dadzie and Dasmani (2010) investigated the influence of gender differences in management on the level of efficiency of food crop farms in Ghana. Stochastic metafrontier production function was used to estimate the efficiency scores in each group and multiple regression model was estimated to verify the determinants of technical efficiency. The estimated technical efficiencies indicated that farms under male farmer's management had higher mean value of production figures relative to the female farmers' farms. The farms under female farmer's management were found to be more efficient and also nearer to the potential output defined by the metafrontier production function compared to the farms owned by males.

Kinkingninhoun-Me dagbe et al. (2010) examined the effect of gender inequality in access to production resources on the income, productivity, and technical efficiency of rice farmers. Using Cobb-Douglas production frontiers, the study found that female rice 
farmers are particularly discriminated against with regard to scheme membership and access to land and equipment, resulting in significant negative impacts on their productivity and income. Although women have lower productivity, they are as technically efficient as men. The findings suggest that there is considerable scope for improving the productivity of women through increasing their access to production resources.

Deere et al. (2010) measured the degree of gender inequality in asset ownership in Latin America. Their estimates of the gender distribution of asset ownership showed that the degree of gender inequality varies considerably according to the type of asset owned by male and female individuals. While the study ascertained gender differentials in different type of asset accumulation, the attribution link to the cause could not be ascertained.

In their contribution to the productivity differences observed in agriculture occasioned by gender roles, Ogisi et al. (2013) examined gender roles in productivity and profitability of cassava in Delta State. Using regression analysis, their findings suggested that development activities in agriculture should be targeted more at the female folk in order to increase their lot as they dominated most production and processing activities in agriculture. While acknowledging their contribution to gender literature in Nigeria, her regression estimates was based on pooled data that did not show any gender disaggregation in their analysis. This has serious implication on policy recommendation suggested by their study.

Conclusions from the literature on gender differences in productivity are mixed. Also, methodological approach to estimating gender differences in productivity differs. Model such as Cobb-Douglas production function, translog production function and multivariate Tobit model have been used based on the type of data available to the researchers. Empirical literature on the effect of gender differences is also limited especially in Africa.

Many studies have also used cross-sectional regression analysis, which methodologically allows controlling for other factors at a given period; and the results of these studies suggest that the gender indicator/variable used was not a statistically significant factor in explaining technology adoption. Most common factors that appear to be statistically significant are education or literacy level, fertilizer, extension services, credit and size of plot, which are all statistically correlated to the gender of the farmer. That is, women farmers surveyed in these studies have lower levels of education or literacy, less access and application of fertilizer, less access to credit, and have smaller plots. These studies emphasized that while the gender of the farmer is not statistically significant, it is the differentiated lack of access to these technologies and complementary inputs and resources between women and men that mainly explain the observed slower adoption rate of technologies by women than men.

This study estimates gender differentials in productivity among rural households with access to improved agricultural technology especially seed varieties. An understanding of the level of productivity with which men and women in the rural areas are operating, particularly where they account for the largest share of the labour force required for increased production of foods and materials from the rural sector, is essential for designing appropriate policies to improve the overall development of rural sector as well as the livelihood of both male and female households. 
This study put a consideration on the sensitivity of productivity estimates to the choice of stratifying gender variable into male and female, while controlling for unobservables where possible. Knowing the source of these productivity differences is a key factor in identifying possible levers for policy intervention to improve productivity across gender line. The study is based on null hypothesis of no significant difference between productivity of male and female in the rural areas in the presence of improved technology.

\section{Method}

The study was carried out in the rural areas of Southwestern geopolitical zone of Nigeria. The southwestern zone lies between latitude $4^{\circ} \mathrm{N}$ and $9^{\circ} \mathrm{N}$ and longitude $3^{\circ} \mathrm{E}$ and $6.2^{\circ} \mathrm{E}$. It is bounded. The climate of Southwest Nigeria is tropical in nature and it is characterized by wet and dry seasons. The temperature ranges between $21^{\circ} \mathrm{C}$ and $34^{\circ} \mathrm{C}$ while the annual rainfall ranges between $1500 \mathrm{~mm}$ and $3000 \mathrm{~mm}$. The wet season is associated with the Southwest monsoon wind from the Atlantic Ocean while the dry season is associated with the northeast trade win from the Sahara desert. The vegetation in Southwest Nigeria is made up of fresh water swamp and mangrove forest at the belt. The data collected were primary in nature. The data were sourced using a wellstructured questionnaire obtained through gender disaggregated data. The data were collected by the researcher assisted by some trained enumerators in the three selected states. Data were collected between the period of June and August in year 2018. A multistage sampling technique was used in selecting the sample. Three (3) states (Oyo, Ogun and Osun) out of the six constituting the sampled zone were purposively selected based on exposure to agricultural seed innovation and agricultural production capacity. The selection of the states was followed by random sampling of eight villages in each of the sampled states. Then, rural dwellers involved in the selected villages were stratified into male and female based on access to the technology innovation. Based on the proportion of male and female in the study area, a total of 197 and 148 male and female rural households were randomly sampled respectively. A total of 345 respondents were sampled.

Gender differentials in productivity were estimated using gender specific CobbDouglas production function following Kinkingninhoun-Me^dagbe et al. (2010) and Peterman et al. (2010). This approach typically was implemented in two main ways: (i) by estimating production functions of male and female managed farm-firm enterprise separately as suggested by Akram-Lodhi (2005); (ii) by pooling observations of male and female households to estimate a productivity outcome. The Cobb-Douglas production function was used because of a number of desirable properties. One of these desirable properties is that $\beta_{\mathrm{i}}$ 's are the elasticities of output with respect to the relevant input. The sum of the $\beta_{\mathrm{i}}$ 's also provides the returns to scale parameter. Another attractive property of the production function is that, econometrically, it is easy to estimate, because in its log form, the parameters are linear and can be estimated easily using the Ordinary Least Squares method.

The conventional method for measuring gender differences in productivity linked to rural agrarian activity through the estimation of Cobb-Douglas is specified as follows: 


$$
\operatorname{Ln} Y_{i}=\sum_{j=1}^{n} \beta_{j} \ln X_{j h}+\sum_{i=1}^{k} \gamma_{i} D_{i}+\mu_{i}
$$

Where $Y_{i}$ is the yield of farm managed by male or female farmer $i ., X_{j h}$ is the quantity of input $j$ used by male or female $h ., D_{i}$ is the vector of the location dummies that represents location specific characteristics. $\beta_{i}$ 's and $\gamma_{i}$ 's are the estimated parameters, $u_{i}$ is an error term summarising the influence of other omitted variables. Input variables that were included in the specific model for the analysis are: Fertilizer measured in kilogram, seeds measured in kilogram., pesticides measured in litres, Labour expressed in man-days/hour., Credit access measured as dummy ( 1 if yes; 0 otherwise), and Education measured in years. Additionally, other explanatory variables that were included are: Farm size, and land ownership (dummy).

With the Cobb-Douglas production function, the realized marginal factor productivity across gender for an input $\mathrm{k}$ (the increase in output resulting from a marginal increase in the input) is the average factor productivity (output per unit input) for the input, $\mathrm{y}_{\mathrm{i}} / \mathrm{x}_{\mathrm{ik}}$, multiplied by the corresponding coefficient $\beta_{\mathrm{k}}$. Depending on the value of magnitude of parameters of each of these explanatory variables, the input is used either in stage one of production function, if the value of the magnitude is greater than or equal to one or in stage two, if the value is less than one but greater than zero (Alimi, 2001).

\section{Results ad Discussion}

\subsection{Socio Economic Characteristics of Respondents}

Socio economic characteristics of respondents vary across gender (Table 1) indicating the existence of gender differences in socio economic characteristics of respondents in the sample area. Age distribution of male differs significantly $(t=1.79, p$ $>0.10)$ from that female. The average farm size of male was found to be significantly $(\mathrm{t}$ $=3.69, \mathrm{p}<0.05)$ higher than that of female. Average farm size of male was 1.7 hectares while that of the female stood at an average of 1.3 hectares. This indicates a significant gender differences in area of land cultivated by male and female in the rural areas. Accumulated years of business experience also differs significantly $(t=1.75, p<0.10)$ between male and female. However, more (5.4\%) female were found to have acquired business experience of between 1 and 5 years relative to 2 per cent statistical value obtained for male. Furthermore, descriptive statistics showed gender differences in years of education of male and female. Average years of education (8 years) of male was found to be significantly different $(\mathrm{t}=4.11, \mathrm{p}<0.05)$ from average years of education of female ( 5 years). Most (46\%) of the male had between 0 and 6 years of education whereas it was majority of female $(72 \%)$ that had similar range of years of education. Most of the male (47\%) and female (51\%) sample in the rural areas acquired land for through inheritance. However, the percentage of male $(21 \%)$ who acquired land through rent was higher relative to female $(16 \%)$. But more female $(15 \%)$ purchased the land compared to male (13\%). The difference in male and female characteristics is in line with the findings of Sofoluwe et al. (2013). 
Published by Hasanuddin University and Asian Rural Sociology Association

Table 1. Socio-Economic Characteristics of Respondents

\begin{tabular}{|c|c|c|c|c|}
\hline Variables & Men & Women & Pooled & $\begin{array}{c}\text { Mean } \\
\text { difference }\end{array}$ \\
\hline \multicolumn{5}{|c|}{ Frequency $(\%$} \\
\hline \multicolumn{5}{|l|}{ Age } \\
\hline $20-30$ & $9(4.5)$ & $2(1.4)$ & $11(3.3)$ & \\
\hline $31-40$ & $16(8)$ & $17(11.7)$ & $33(9.6)$ & \\
\hline $41-50$ & $63(31.9)$ & $71(48.2)$ & $134(38.8)$ & $1.79 *$ \\
\hline $51-60$ & $79(40)$ & $45(30.7)$ & $124(36)$ & \\
\hline $61-70$ & $24(12.1)$ & $13(18.9)$ & $37(10.8)$ & \\
\hline$>70$ & $6(3)$ & $0(0)$ & $6(1.8)$ & \\
\hline Mean & 52.11 & 49.82 & 51.13 & \\
\hline Standard deviation & 9.80 & 8.19 & 9.2 & \\
\hline \multicolumn{5}{|l|}{ Farm size } \\
\hline$<1$ & $41(20.7)$ & $56(38.0)$ & $97(28.3)$ & \\
\hline $1-2.5$ & $137(69.5)$ & $78(52.7)$ & $215(62.3)$ & \\
\hline $3-3.5$ & $16(8.1)$ & $13(9.5)$ & $30(8.7)$ & \\
\hline $4-4.5$ & $1(0.5)$ & $0(0)$ & $1(0.3)$ & $3.69 * * *$ \\
\hline$\geq 5$ & $2(1.0)$ & $0(0)$ & $2(0.6)$ & \\
\hline Mean & 1.68 & 1.29 & 1.52 & \\
\hline Standard deviation & 0.84 & 0.83 & 0.86 & \\
\hline \multicolumn{5}{|l|}{ Years of experience } \\
\hline $1-5$ & $4(2)$ & $8(5.4)$ & $12(2.5)$ & \\
\hline $6-10$ & $47(23.9)$ & $36(24.32)$ & $83(24.1)$ & $1.75^{*}$ \\
\hline$>10$ & $146(74.1)$ & $104(70.27)$ & $250(73.4)$ & \\
\hline Mean & 19.38 & 17.82 & 18.71 & \\
\hline \multirow{2}{*}{\multicolumn{5}{|c|}{ Years of education }} \\
\hline & & & & \\
\hline $0-6$ & $91(46.1)$ & $106(71.6)$ & 197(57.1) & \\
\hline $7-12$ & 61(30.9) & $22(14.9)$ & $83(24.1)$ & $4.11^{* * *}$ \\
\hline$>12$ & $45(23)$ & $20(13.6)$ & $65(18.8)$ & \\
\hline Mean & 8.16 & 5.30 & 6.93 & \\
\hline Standard deviation & 5.58 & 1.43 & 5.69 & \\
\hline \multicolumn{5}{|c|}{$\begin{array}{l}\text { Mode of land } \\
\text { acquisition }\end{array}$} \\
\hline Rent & $38(20.7)$ & $22(16)$ & $60(18.7)$ & \\
\hline Inherited & $86(47)$ & $70(51.1)$ & $156(48.8)$ & \\
\hline Purchased & $24(13.1)$ & $21(15.3)$ & $45(14.1)$ & -0.73 \\
\hline Leased & $27(14.8)$ & $16(11.7)$ & $43(13.4)$ & \\
\hline Gift & $8(4.4)$ & $8(5.8)$ & $16(5.0)$ & \\
\hline
\end{tabular}

Source: Data Analysis, 2018

$*, * * *$, significant at $10 \%$ and $5 \%$ respectively

\subsection{Gender Differentials in Average Productivity}

Results in Table 2 show productivity indicators disaggregated by gender. The average yield of all the sample was 1.17 tons/ha. The comparison of these values across gender showed that the average yield of men was 1.35 tons/ha while that of the women was 1.02 tons/ha; the estimated yield difference of 0.33 tons/ha was statistically significant at 5\% level. This result showed that men had higher average yield than women. This is in line with Kinkingninhoun-Medagbe et al. (2010) who attributed gender differences in average productivity to inability of women farmers to cultivate owned land, but land borrowed from their husbands or from their family members. In 
most cases, women have access to marginal and small pieces of land. Men with access to improved technology have significantly $(\mathrm{p}<0.05)$ higher productivity per unit of most of the inputs available (seeds, pesticides and labour). Generally, the result indicates that the estimated productivities of women with similar access to productivity technology as men are significantly lower than those of men.

Table 2: Gender Differentials in Average Productivity

\begin{tabular}{lcccc}
\hline \multicolumn{1}{c}{ Average productivity of } & Male & Female & Pooled & Mean Difference \\
\hline Land (ton/ha) & $1.35(0.63)$ & $1.02(0.69)$ & $1.17(0.67)$ & $1.97^{* *}$ \\
Seeds $(\mathrm{kg} / \mathrm{kg})$ & $4.58(2.54)$ & $4.51(2.56)$ & $4.45(2.55)$ & $2.97^{* * *}$ \\
Fertilizers $(\mathrm{kg} / \mathrm{kg})$ & $2.07(0.07)$ & $2.09(0.71)$ & $2.08(1.03)$ & 1.45 \\
Pesticides (ton/lt) & $6.07(0.14)$ & $6.02(0.15)$ & $6.05(0.14)$ & $2.59^{* * *}$ \\
Labour(kg/man day) & $6.24(1.32)$ & $6.15(1.25)$ & $6.21(2.29)$ & $3.46^{* * *}$ \\
\hline
\end{tabular}

Source: Data analysis, 2018

The numbers in parentheses indicate the standard deviation

***, significant at $5 \%$ level

\subsection{Estimated Cobb-Douglas Production Function}

Results of the estimation of the Cobb-Douglas production function are presented in Table 3. From the findings, gender differentials in productivity could be attributed to differences in the use of factor inputs such as farm size and quantity of seeds as well as gender factors such as land ownership and years of education. Specifically, parameter estimates of Cobb-Douglas frontier production function showed that yield (productivity) was positively and significantly $(\mathrm{p}<0.05)$ influenced by size of land holdings. A $10 \%$ per cent increase in farm size of men $(\beta=0.23, t=5.78)$ resulted in 23 per cent increase in yield (productivity) while a similar $10 \%$ per cent increase in size of women's land ( $\beta$ $=0.11, \mathrm{t}=4.07$ ) resulted in 17 per cent increase in their farmland productivity. The magnitude of the parameters indicates that both men and women fully utilized land resource and operated at rational level (stage two) of production. One of the implications of this finding is that, in general, managerial incompetence cannot be implicated as one of the causes of the estimated gender differentials in productivity.

Coefficient of individual gender factor such as land ownership was positive for both male and female production function but the variable was only significant $(p<0.05)$ for male $(\beta=0.24, t=2.58)$. This result showed that ownership of land has a significant influence on the estimated productivity of the farm business managed by male. The result implied that one of the main causes of estimated difference in productivity between male and female farmers is the difference in land ownership. Furthermore, education which is another gender factor and a measure of human asset and managerial capacity significantly $(\mathrm{p}<0.05)$ increased the productivity of men $(\beta=0.11, \mathrm{t}=3.04)$ and women $(\beta=0.07, t=3.86)$. But, the value of the magnitude showed that female in the rural areas benefit less from education than male. A possible explanation is that as women get more education, they tend to shift their focus and efforts from farm business activities to other off-farm and income generating activities in addition to household chores. Thus, the number of hours spent in farm business decreases at a much faster rate than men. 
Published by Hasanuddin University and Asian Rural Sociology Association

Table 3: Estimated Cobb Douglas Production Function

\begin{tabular}{llllll}
\hline \multirow{2}{*}{ Variables } & \multicolumn{2}{c}{ Male } & \multicolumn{2}{c}{ Female } & Pooled \\
\cline { 2 - 6 } & Estimate & t-ratio & Estimate & t-ratio & Estimate (t-ratio) \\
\hline Farm size & 0.23 & $5.78^{* * *}$ & $0.11^{* * *}$ & $4.07^{* *}$ & $0.24(7.22)^{* * *}$ \\
Seeds & 0.47 & $1.78^{*}$ & $0.79^{* * *}$ & $2.19^{* *}$ & $0.58(2.77)^{* * *}$ \\
Fertilizers & -0.02 & -0.87 & -0.16 & -0.89 & $-0.05(-0.49)$ \\
Pesticides & 0.33 & $1.68^{*}$ & -0.28 & -1.06 & $-0.03(-2.06)$ \\
Labour & 0.18 & $2.53^{* *}$ & 0.09 & $2.24^{* *}$ & $0.09(3.94)^{* * *}$ \\
Land ownership & 0.24 & $2.58^{* * *}$ & 0.26 & 1.47 & $0.34(5.06)^{* * *}$ \\
Education & 0.11 & $3.04^{* * *}$ & 0.07 & $3.86^{* * *}$ & $0.08(2.33)^{* * *}$ \\
Constant & 8.50 & $7.18^{* * *}$ & 10.29 & $6.57^{* * *}$ & $9.24(4.88)^{* * *}$ \\
$\sigma^{2}$ & 0.017 & & 0.208 & & 12.11 \\
$\mathrm{R}^{2}$ & 0.70 & & 0.68 & & 0.69 \\
Sample size $(\mathrm{N})$ & 197 & & 148 & & 345 \\
\hline
\end{tabular}

Source: Data Analysis, 2018

$*, * *, * * *$, significant at $10 \%, 5 \%$, and $1 \%$ respectively

Values in bracket are t-value

\subsection{Gender Differentials in Marginal Productivity}

Table 4 presents the results of the estimated marginal factor productivity indices disaggregated by gender. The marginal productivity (MP) method, based on the response coefficients of the inputs was utilized to analyze the sensitivity of productive inputs to productivity. The marginal productivity of a factor implies the change in the total yield corresponding to a unit change in the factor input, based on the assumption that other factors are fixed at their geometric mean level. A positive value of MP of any input variable, therefore, identifies that the total output is increasing with an increase in input. Thus, men and women should not stop increasing the use of variable inputs so long as the fixed resource is not fully utilized. A negative value of MP of any variable input indicates that every additional unit of input starts to diminish the total output of previous units; therefore, it is better to keep the variable resource in surplus rather than utilizing it as a fixed resource.

The estimated marginal productivity results showed that men in the rural sectors have higher mean marginal productivities (MP) of both fixed and variable inputs including land, pesticides and labour while the realized marginal productivity for only the variable inputs such as seeds and fertilizers are higher for women. Specifically, marginal productivity estimates showed that MP of land was significantly $(\mathrm{p}<0.05)$ higher for male $(\mathrm{MP}=0.31)$ than female $(\mathrm{MP}=0.11)$ respectively, with an estimated difference of 0.20 . The finding corroborates Kinkingninhoun-Medagbe et al. (2010) who also observed lower MP for Beninese women involved in rice production. This results lead to the rejection of null hypothesis of no significant difference between yield of male and female farmers. However, the marginal productivity of seeds, fertilizer, pesticides and labour were $2.15,-0.04,2.0$, and 1.12 respectively for male farmers. Estimated MP of seeds, fertilizer, pesticides and labour for female farmers were 3.56, $0.33,-1.69$ and 0.55 respectively.

An increase in allocation of land, seeds, and labour to the cultivation of improved maize variety would increase the yield of the farms managed by male farmers using improved maize variety by $0.21,2.15$ and 1.12 respectively. Similar increase in allocation of the resources would lead to an increase in the marginal productivity of the female by $0.18,3.56$ and 0.55 respectively. However, every additional unit of pesticides 
used by female starts to diminish the total output of previous unit; therefore, it would be better for female to keep the variable resource in surplus rather than utilizing it in a fixed resource contrary to what is obtainable for male.

Table 4: Estimated Marginal Productivity Differences

\begin{tabular}{lllll}
\hline MP of & Male & Female & Pooled & Mean difference \\
\hline Land & 0.31 & 0.11 & 0.29 & $2.14^{* *}$ \\
Seeds & 2.15 & 3.56 & 2.58 & $1.99 * *$ \\
Fertilizers & -0.04 & -0.33 & -0.10 & $2.08^{* *}$ \\
Pesticides & 2.00 & -1.69 & -0.18 & $1.87^{*}$ \\
Labour & 1.12 & 0.55 & 0.56 & 1.43 \\
\hline
\end{tabular}

Source: Data Analysis, 2018

Note: The numbers in parentheses indicate the standard deviation

$*, * *$, significant at $10 \%$ and $5 \%$ respectively.

\section{Conclusions}

Estimates of gender differentials in productivity showed that productivity was significantly lower for rural women than men in the presence of improved productive technology. The estimated difference of 0.33 tons/ha and 0.20 tons/ha in average and marginal productivity was obtained for men and women, respectively. Significant factors affecting gender differentials in productivity were land ownership and years of education. Since differences were observed in productivity of male and female, it is recommended that relevant stakeholders should strive to close the gender gap in ownership of land, educational attainment and access to other productive inputs in the rural sector.

\section{Acknowledgements}

The author acknowledges the full support of Agricultural and rural development agencies in Oyo, Ogun and Osun States of Nigeria during the course of this study.

\section{References}

Adekambi, S.A., Diagne, A., Simtowe, F.P., and Biaou, G. (2009). The impact of agricultural technology adoption on poverty: The case of NERICA rice varieties in Benin. Contributed Paper prepared for presentation at the International Association of Agricultural Economists, August Conference, Beijing, China.

Agboh-Noameshie, A.R., Kinkingninhoun-Medagbe, F.M., and Diagne, A. (2007). Gendered impact of NERICA adoption on farmers' production and income in Central Benin. Conference proceedings of AAAE Conference.

Akram-Lodhi, A. H. (2005). Intrahousehold resource allocation: a feminist economics perspective. The Hague: ISS Lecture FDE 300 (2).

Alene, A.D, Manyong, V.M., Gockowski, J., Coulibaly, O., and Abele, S. (2006). A framework for conceptualizing impact assessment and promoting impact culture at IITA. IMPACT, IITA, Ibadan, Nigeria.

Dadzie, S.K.N., and Dasmani, I. (2010). Gender difference and farm level efficiency: Metafrontier production function approach. Journal of Development and Agricultural Economics, 2(12): 441-451. 
Deere C. D., Alvarado, G.E., and Twyman, J. (2010). Poverty, Headship, and Gender Inequality in Asset Ownership in Latin America: Working Paper \#296 Center for Gender in Global Context, Michigan State University.

Deji, O.F. (2011). Gender and Rural development. Spektrum 106, Berlin series on society, Economy and Politics in Developing Countries. $1 \& 2$.

Heikkilä, A., Myyrä, S., and Pietola, K. (2012). Effects of economic factors on adoption of robotics and consequences of automation for productivity growth of dairy farms. Factor Markets Working Papers No. 32

Kinkingninhoun-Me^dagbe' F.M. Diagne, A. Simtowe, F. Agboh-Noameshie, A.R. Ade'gbola, P.Y (2010). Gender discrimination and its impact on income, productivity and technical efficiency: evidence from Benin, Agric. Hum. Values, 27:57-69.

Odurukwe, S.N. (2003). Gender differences in adoption of recommended improved cassava production technologies in Imo state, Nigeria. JASR, 3(2): 126-134.

Ogisi, O. D., Toritseju, B., and Bennet, O. A. (2013). Gender roles in the productivity and profitability of cassava (Manihot esculenta) in Ika south and Ika north east local government areas of Delta state, Nigeria. World Applied Sciences Journal, 24 (12): 1610-1615.

Padmaja, R., Bantilan M.C.S., Parthasarathy, D., and Gandhi, B.V.J. (2006). Gender and social capital mediated technology adoption. Impact Series no. 12. International Crops Research Institute for the Semi-Arid Tropics. Pp. 48

Peterman, A., Quisumbing, A., Behrman, J., and Nkonya, E. (2010). Understanding gender differences in agricultural productivity in Uganda and Nigeria. Poverty, Health, and Nutrition Division, IFPRI

Quisumbing, A. R. (1996). Male-female differences in agricultural productivity: Methodological issues and empirical evidence. World Development, 24(10): $1579-1595$.

Quisumbing, A., and Pandolfelli. L. (2010). Promising approaches to address the needs of poor female farmers: Resources, constraints, and interventions. World Development 38(4): 581-592.

Ragaza, C. (2012). Gender and Institutional Dimensions of Agricultural Technology Adoption: A Review of Literature and Synthesis of 35 Case Studies. Selected Poster prepared for presentation at the International Association of Agricultural Economists (IAAE) Triennial Conference, Foz do Iguaçu, 18-24 August, Brazil.

Schmidt, L., and Sevak, P. (2006) Gender, Marriage, and Asset Accumulation in the United States, Feminist Economics, 12(1\&2): 139- 166.

Sofoluwe, N.A., Tijani, A.A and R.O. Kareem (2013) Socio-Economic Factors Influencing the Use of Botanicals in Cocoa Pest Management, Thai journal of agricultural sciences, 46(1):29-35

Sofoluwe N. (2015) Gender Differentials in productivity and asset acquisition among improved maize variety adopters in Southwestern Nigeria. Unpublished $\mathrm{PhD}$ thesis submitted at Obafemi Awolowo University, Ile-Ife, Osun State. 
Thapa, S. (2009). Gender differentials in agricultural productivity: Evidence from Nepalese household data. University of Trento, Department of Economics, Trento, Italy. Electronic paper.

World Bank, (2007). Gender and Economic Growth in Kenya. Washington, DC: World Bank. 